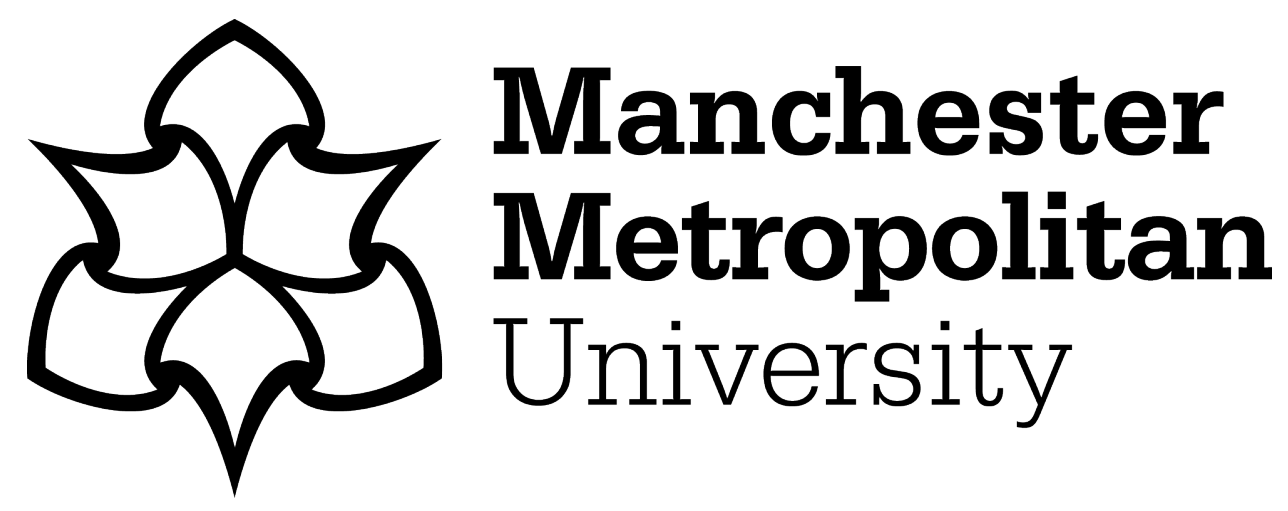

Jones, Katherine ORCID logoORCID: https://orcid.org/0000-0002-80904557, Ahmed, Anya ORCID logoORCID: https://orcid.org/0000-0002-61640656, Madoc-Jones, Iolo, Gibbons, Andrea, Rogers, Michaela and Wilding, Mark (2019) Working and homeless: exploring the interaction of housing and labour market insecurity. Social Policy and Society, 19 (1). pp. 121-132. ISSN 1474-7464

Downloaded from: https://e-space.mmu.ac.uk/623603/

Version: Published Version

Publisher: Cambridge University Press (CUP)

DOI: https://doi.org/10.1017/S1474746419000332

Please cite the published version 


\title{
Working and homeless: exploring the interaction of housing and labour market insecurity
}

Katy Jones, Manchester Metropolitan University katy.jones@mmu.ac.uk

Anya Ahmed, University of Salford A.Ahmed@salford.ac.uk

Iolo Madoc-Jones, Wrexham Glyndwr University i.m.jones@glyndwr.ac.uk

Andrea Gibbons, University of Salford A.R.Gibbons1@salford.ac.uk

Michaela Rogers, University of Sheffield m.rogers@sheffield.ac.uk

Mark Wilding, University of Salford M.A.Wilding@salford.ac.uk

\begin{abstract}
Alongside an increasing focus on 'prevention', moving homeless adults into work is frequently considered an important part of helping them overcome homelessness and sustain an 'independent' life. However, a growing evidence base shows that work does not always offer the means to escape poverty, and many in employment face housing insecurity. Relatedly, there is increasing concern about the phenomenon of 'in-work homelessness'. Drawing on new data from a study of people's experience of homelessness in Wales, this paper considers the hitherto underexplored topic of being both in work and homeless. The article provides a critical examination of how homelessness policy operates in practice, through presenting evidence of the experiences of a marginalised group (namely, working homeless people as users of homelessness services). It also considers how policy and practice could be modified to improve outcomes for homeless people and how prevention could play out in other contexts and welfare regimes.
\end{abstract}

Key words: homelessness, housing, employment, poverty, conditionality

\section{Introduction}

A focus on prevention in international homelessness policy stems from a belief that homelessness is something that can, and should, be prevented (Shin et al. 2001). Alongside an increasing focus on 'prevention', moving homeless adults into paid employment is frequently presented as an important part of the 'answer' to homelessness as well as a range of other social problems (Shier et al. 2012; Gerrard, 2017). Indeed, in response to recent rises in rough sleeping in the UK, the then Prime Minister Theresa May emphasised being in work as a long-term solution (Scheerhout, 2017).

Consequently, homelessness and broader welfare policy in the UK and elsewhere has involved shifts to an increasingly interventionist approach to welfare support and services for homeless adults, many of which include movement into paid employment as a central component (Jones, 2019; Batty et al. 2015; Gerrard, 2017). These policy developments are based on assumptions that individuals who are earning an income through paid work will be able to meet their basic needs and live a stable and independent life (Shier et al. 2012). Whilst for many, labour market participation may be the main way to avoid poverty and social exclusion (Ray et al. 2014), this straightforward link between paid work and security is increasingly being called into question, as wages have not kept pace with rising living costs and labour market opportunities are characterised by endemic low pay and precarity (Standing, 2011; Tinson et al. 2016).

Whilst low pay, in-work poverty and related concepts have received growing attention in the literature to date (Tinson et al, 2016; Hick and Lanau, 2018), 'in-work homelessness' remains a comparatively underexplored issue. This article addresses that neglect and presents new evidence about the experiences of working people facing homelessness in Wales. Whilst the paper provides a critique of how policy operates and how practice might be modified to improve outcomes for working homeless people in that context, the examination has relevance beyond Wales. Insecurity in both labour and housing markets is a 'common characteristic of capitalist economies' (Gerrard, 2017: 54), thus its 
findings are relevant to other contexts where individual responsibilities to engage in paid work are emphasised but the structural causes of low pay (for example, reduction in trade union membership, privatisation and labour market deregulation) and insecure and unaffordable housing are left unchecked (Lloyd and Mayhew, 2010). As the incidence of both 'in-work poverty' and housing costs remain high, how this can influence the lives of some people should be better understood.

The remainder of the article consists of five parts. First, an overview of the existing evidence base on in-work homelessness and related concepts is presented, including its limitations and the contribution this paper makes. Second and third, key policy is introduced before the methods and sample are outlined. The fourth section considers the relationship between work and homelessness amongst a diverse group of people facing homelessness. Finally, concluding remarks and implications for policy and practice are presented. It addresses the aims of the thematic issue through providing a critical examination of how homelessness policy operates in practice, through presenting new evidence of the experiences of a marginalised group (namely, working homeless people as service users), and considers how policy and practice could be modified to improve outcomes for homeless people and how prevention could play out in other contexts and welfare regimes.

\section{In-work homelessness: overview of existing literature}

The term 'homelessness' encompasses a variety of forms of housing exclusion, including rough sleeping, living in hostels and temporary supported accommodation, and more 'hidden' forms such as sofa surfing and overcrowding. Statutory homelessness includes households who seek assistance from local authorities due to the loss/imminent loss of accommodation. Broadly speaking, homelessness and housing exclusion in its varying forms has been increasing across the EU in recent years (FEANTSA, 2018). However, comparing trends across nations is challenging due to varying definitions and data collection methods. In the UK, patterns of homelessness vary across the devolved nations. In England, for example, rough sleeping has increased dramatically over recent years, doubling between 2010 and 2015. In Wales, as in other areas of the UK, homelessness due to a loss of rental tenancy has seen recent increases - between 2009/10 and 2014/15 homelessness occurring due to a loss of rental tenancy increased by 20 per cent (Fitzpatrick et al. 2016).

Accurate and comparable data on 'in-work homelessness' is similarly lacking both in the UK and internationally. Definitions of 'homelessness' and 'being in employment' vary widely, and disparities in figures represent ad hoc data collection activities across different parts of the homelessness sector and between countries (Busch-Geertsema, 2010). The European Federation of National Organisations Working with the Homeless (FEANTSA) estimates that the proportion of those experiencing homelessness at the same time as engaging in paid work ranges from less than 5 per cent to 25 per cent across Europe (FEANTSA, 2014). In the UK, a recent survey of the homelessness sector (Homeless Link, 2016) suggests that 9 per cent of 'homeless service users' are in employment - this proportion rises to one fifth of young people living in homeless accommodation. Research from Shelter (a national homelessness charity) found that 55 per cent of homeless families in temporary accommodation are in work (Shelter, 2018).

Whilst research on 'in-work homelessness' is scarce, the evidence base on a related concept, namely, 'in-work poverty', and its incidence is growing - both in the UK and in other countries (Tinson et al, 2016; Hick and Lanau, 2018). The experience of poverty has been identified as a 'key contributory factor' to homelessness (Johnsen and Watts, 2014). In 2016, 8.6 per cent of employed people were at risk of poverty in the United Kingdom, slightly below the EU average of 9.6 per cent. The share of employed persons at risk of poverty rose in most EU Member States over the past decade (Eurostat 2018).

However, as Fitzpatrick and Stephens (2014) note, caution is needed in making cross-national comparisons and undertaking 'welfare regime analysis' of responses to homelessness and other social 
issues, not least due to a lack of comparable cross-national data on socially marginalised populations. Furthermore, as Johnsen and Watts (2014: ii) note, the causal influence of poverty on homelessness:

'is determined in part by macro-level structural conditions such as welfare regimes, housing and labour markets, but also complex interactions between these and microlevel factors such as individual vulnerabilities...the effects of poverty as a causal influence can be mediated...by a number of factors such as the degree of protection provided by welfare regimes, support programmes, and individuals' access to social, economic and/or human capital'.

It has also been suggested that variations in the extent of in-work homelessness, and how it is experienced may also result from differences in 'broader patterns of homelessness - i.e. whether it is more strongly associated with complex support needs as opposed to affecting wider segments of people with very low incomes' without complex support needs (FEANTSA, 2014: 75). The relationship between 'in-work poverty' and 'in-work homelessness' therefore requires further exploration. However, as Gerrard (2017) notes, insecurity in both labour and housing markets is a 'common characteristic of capitalist economies' (Gerrard, 2017: 54) so the findings presented here are likely to be relevant to those in other contexts and welfare regimes.

Beyond headline statistics, a small number of studies in the UK and elsewhere have explored the issue of 'in-work homelessness' qualitatively (Shier et al. 2012; Hough et al. 2013). These mostly focus on the experiences of 'single homeless people', and those residing in hostels and emergency accommodation. Shier et al. (2012)'s Canadian study, for example, involved interviews exploring the labour market experiences of people working and accessing emergency accommodation services. Their study identified a high incidence of temporary and insecure work, and highlighted ways in which homelessness services could present challenges for working homeless people, including a lack of flexibility around the working patterns of individuals (for example, through strict exit and entry time restrictions at shelters).

Related to this, a small number of studies have focused on the potential of labour market entry to facilitate transition out of homelessness (McNaughton, 2008; Hough et al. 2013). Here there has been a tendency to focus on the potential of particularly marginal forms of employment. Gerrard (2017), for example, explored the informal and often marginalised work experiences of homeless 'street press' sellers, working in cities in the UK, US and Australia. Situated in low paid work at the precarious end of the jobs market, they faced few opportunities to progress to higher paid, stable employment. Such work tended to reinforce the position of homeless people outside, or on the margins of mainstream employment (FEANTSA, 2007), where they continued to be at risk of recurrent spells of unemployment and/or homelessness (Hough et al., 2013). Focusing on single homeless people and those engaged in more precarious forms of employment is entirely justified, as it is here where some of the most extreme forms of social exclusion are found. However, as this paper will show, 'in-work homelessness' is not confined to single homeless workers and/or those engaging in the most precarious forms of work.

\section{Work, housing and homelessness - UK policy context}

The research presented in this article took place in Wales, a devolved country in the United Kingdom. Using powers from Devolution in 1998, the Welsh Government has restructured homelessness support and services around prevention following the introduction of the Housing Act (Wales) 2014. As part of this, local authorities were given new duties to help prevent homelessness for all who ask for assistance. Local authorities were required to work in a person-centred, flexible way, and it was also made easier for them to discharge their homelessness duties by offering accommodation in the private rented sector (see Ahmed and Madoc-Jones, this special issue for more detail).

These legislative changes have taken place within a wider context UK welfare reform, which is relevant to those exploring the interaction of housing and labour market insecurity. Of particular significance has been continued shifts toward increasingly interventionist approaches to welfare support and services 
for homeless adults, many of which centre on movement into paid employment. Those out of work and in receipt of state benefits, for example, are increasingly subject to 'welfare conditionality', whereby they must demonstrate engaging in sufficient work-focused activities in exchange for an out-of-work income. Failure to meet these demands may result in benefit 'sanctions', involving a loss of income for claimants. The recent introduction of Universal Credit, a new benefit which rolls six existing benefits into one monthly payment, has involved a further ratcheting up of conditionality to 'ubiquitous' levels (Dwyer and Wright, 2014), and, significantly, may involve the extension of conditionality beyond those out of work to those on a low income. Whilst 'in-work conditionality' is an evolving policy, recent trialling activity has involved the application of work-related conditions to those in work, which in some cases has resulted in those on a low income being subject to benefit sanctions (DWP, 2018). Outside of the social security system, conditionality has crept into other domains, including social housing and homelessness policy and practice. The Localism Act (2011), for example, allowed social housing providers to offer fixed-term tenancies, which may or may not be renewed on the basis of factors including, amongst other things, a tenant's income or employment status (Fitzpatrick and Watts, 2018).

Other relevant aspects of welfare reform include cuts to the financial support available to help those on no or low income to cover housing costs. Whilst financial support is available to help towards housing costs through Housing Benefit (soon to be replaced by Universal Credit), a new 'benefit cap' limits the amount of benefits that any one household can receive to $£ 20,000$ per annum (outside London). This is predicted to impact most on larger families and those living in high cost areas $(\mathrm{CIH}, 2016)$. Private sector landlords have also been found to discriminate against claimants and often refuse to let their properties to those in receipt of Housing Benefit (Shelter, undated). There are concerns that landlords will extend this discriminatory practice to those in receipt of Universal Credit which subsumes Housing Benefit, Income Support, income-based Jobseeker's Allowance, income-related Employment Support Allowance, Working Tax Credit and Child Tax Credit. Furthermore, as Universal Credit is paid to claimants (rather than direct to landlords, as was the case under Housing Benefit), the reluctance of landlords to let to claimants may increase. The implications of this wider policy context are considered in the final section of this article.

\section{Methods and sample}

This paper presents analysis of new data generated in qualitative semi-structured interviews with 18 working people who approached their local authority as homeless, or at risk of homelessness. Interviewees were part of a larger study exploring the impact of new homelessness legislation in Wales (Housing Act (Wales) 2014). Interviews took place across six local authority areas (both rural and urban) between October 2016 and January 2017. Follow up interviews with five participants were conducted in June/July 2017. Participants were primarily identified through local authority housing offices, and were conducted in a range of settings, including local authority offices, hostels, shelters, and over the phone. With the participant's permission, interviews were digitally recorded and transcribed verbatim. The study was undertaken following ethical approval from University of Salford's Research Ethics Review Panel. The interviews focused on participants' experiences of accessing and navigating new services, introduced in Wales from 2015 to prevent or address homelessness. As such, 'in-work homelessness' was not a central focus of the interviews. However, across relevant respondent accounts, it was clear that an individual's status in the labour market could intersect with their housing exclusion and insecurity. This paper therefore presents a thematic analysis of those interviews wherein the respondent indicated that they were in paid work.

Thirteen respondents identified themselves as male and five as female. Sixteen identified as White British, and two identified as Black British. Ages ranged from 20 to 56. In terms of household composition, 13 participants were single, four were lone parent households, and one was part of a couple with young children. At the time of their first interview, that is to say when they first approached housing services for help and support in relation to homelessness, participants were living in a range of different housing situations including, sofa surfing, living with relatives in overcrowded properties, rough sleeping, private renting, social renting, living in hostels, emergency accommodation, caravans, 
and hotels. In several cases, participants were alternating between sofa-surfing and living on the streets. As work was not a key focus of the study, data on the nature of work were not consistently collected across the sample. Seven did not give any details about the nature of their employment contract. However six indicated that they were working full-time, two reported having variable hours (zero hours contracts and agency work, although did not specify whether this was on a part-time or full-time basis), and three were working part-time on a regular basis - mostly to fit around caring responsibilities for small children.

\section{Analysis}

Key findings from the thematic analysis are presented in three main sections: (i) the relationship between work and homelessness; (ii) experiences of support from the housing service; and (iii) the necessity of alternative support and resources.

\section{The relationship between work and homelessness}

As indicated above, all participants were in work at the time of interview, although the nature of this work varied. Some were precariously employed, through agency work or zero hours contracts. However, the sample was not restricted to those in the most marginal forms of employment, as has been explored in previous research on in-work homelessness (for example, Shier et al, 2012, McNaughton, 2008; Gerrard, 2017). Indeed, for some, their experience in the labour market was a positive one. One participant, for example, spoke enthusiastically about their work and their prospects of progression from a full-time customer service position.

I love my job... I'm looking at progressing there. I've had a couple of interviews, so I'm progressing already. They guy there is very keen on having me progress up (Respondent 3)

However, across the interviews, participants described their struggle to survive on a low income and to access housing options as they faced the prospect (or experienced) homelessness. Even those in regular, full-time work struggled to put aside enough of their wage to cover the deposits and letting fees required by landlords and estate agents to access accommodation in the private rental market.

It's just so expensive and I would just get to a point where I was spending like £200 a week on hotel rooms and I couldn't save any money for [a deposit] (Respondent 3)

For many, retaining their work was clearly important. Yet the challenges of sustaining work in the face of homelessness were evident. One participant who was rough sleeping described struggling to be presentable and maintain hygiene standards as he was unable to wash his work clothes:

I was getting back, well, home to the field, stinking, smelling of rubbish. I've got nowhere to wash, nowhere to wash my clothes. (Respondent 5)

The interaction of housing and labour market insecurity could also have impacts beyond the individual making a homelessness application. For example, one participant who was a lone parent with a young child, explained how needing to live in overcrowded circumstances with her own mother was also adversely impacting on her mother's working life. Her mother's job had to be managed alongside supporting her adult daughter and grandchild as they were unable to house themselves. However, the disruption occurring as a result of this living arrangement could make her working life more challenging:

[My mum] works in a hospital. If he's noisy at night... it wakes her, it disturbs her. It's not convenient, it's not a good setup (Respondent 1).

Most respondents had become homeless whilst in work. Homelessness had not occurred through the loss of work, and so was not a direct consequence of their experiences in the labour market. Instead, the immediate causes included eviction, relationship breakdown and the ending of short-term tenancy 
agreements. High upfront costs associated with starting a new tenancy (for example, deposits and lettings agency fees) could then prove prohibitive. Despite having a history of tenancy sustainment (for example, with track records of regular rent payments), participants had been unable to weather the unexpected financial shock of losing their home and access enough financial resource to smoothly transition into a new one. One key barrier to accessing accommodation therefore related to a limited supply of affordable housing. Being on low incomes afforded by wages and Housing Benefit excluded participants from properties in the private rented sector:

We looked at various different properties, but they were all way out of budget for what we would have been entitled to in [Housing Benefit], well with my wages... If you're a family on a low income... there is not a lot in the private sector out here to work with. (Respondent 7)

Even where participants could afford properties, they continued to be excluded from the private rented sector due to an unwillingness on the part of landlords to accept tenants in receipt of Housing Benefit (a benefit claimed by those both out of work and working on a low income), a common practice, as noted above (see Shelter, undated). One participant, for example, who was claiming Housing Benefit due to her need to work part-time in order to balance work and childcare, talked at length about their frustrations of being excluded from private accommodation on this basis:

Every time I phoned a letting agent they would just turn me away straightaway... they turn around and say, 'Actually you're not able to have this property because you'll be on Housing Benefit.' I'm working as well, I'm working part-time, so it would just be a top up. (Respondent 2)

Being in work also placed additional constraints on the options available to some respondents. This related to the need to find affordable accommodation within travelling distance of their workplace and/or near public transport hubs. In particular, limited choice in rural areas was worsened by poor local transport infrastructure. One woman, for example, who was living in a caravan with her partner and small children, had been offered temporary accommodation but had felt she needed to turn this down because it was nowhere near her places of work:

We were offered temporary housing but they didn't have anything in [places of work] ...I work in a care home where I do late shifts. and I also work in a local pub and sometimes I don't finish until 1:00am ... I can't be walking to a couple of villages across and I can't afford taxis because both jobs I have are both minimum wage. (Respondent 7)

\section{Experiences of 'support' from the housing service}

Participants were commonly given information about local landlords and lettings agencies, which they were expected to follow up in order to resolve their homelessness.

Well they gave me a list of places like agencies, letting agencies... advised me to go to housing associations, and to call up landlords (Respondent 4)

Despite bonds being available to help cover the costs of a deposit, this does not appear to have been widely communicated to this group of respondents.

Overall, simply providing information and sending respondents on their way was not considered helpful, as this was not sufficient to help participants to overcome their housing difficulties. As noted above, this was due in large part to landlords refusing to let to individuals in receipt of Housing Benefit, irrespective of whether or not those persons were in some sort of employment. Despite staff being aware of these structural constraints, support offered by the housing service appeared to offer no practical solution to such futile searching: 
When I spoke to the Housing Options officer... he just said that they would also keep an eye out for me, and if they find anything suitable they would contact me, but just to keep doing what I was doing. It hasn't got me anywhere, it's not working (Respondent 2)

For some, a lack of housing options in the face of homelessness related to their status as workers. Several participants made explicit observations about a lack of appropriate support for 'working and homeless' people. For example, for one respondent, his working status and associated need to stay 'professional' meant the offer of a hostel was unsuitable:

They said... if I don't have anywhere to live they can refer me to a hostel, which is the best they can do and I can appreciate that, but you know when you're working in a professional place and you've got to wear a shirt and tie to work with shoes and ironed and pressed I don't really want to have floor space - I don't even know if the shoes are still going to be there in the morning (Respondent 4)

For some, supported accommodation (whereby both housing and support services are offered together, including homelessness hostels) was not a realistic prospect. This was because being in work they would have been required to use a significant proportion of their income to cover rent and supported living expenses (these costs are covered for those with no income):

I got a job and then it was a big building and the support, you know, you end up paying for the support and it was a lot. Unless I was a doctor I couldn't afford to live there. (Respondent 6)

Rather than address the needs of homeless people in work, such individuals could be advised to return to live with their family even though this option would have resulted in loss of work:

They were going to phone my dad and see if I could stay there, but if I do that then

I'd lose my job. I can't afford to lose my job. (Respondent 3)

\section{The necessity of alternative support and resources}

As shown above, participants gave accounts of falling through the holes of the 'safety net'. They struggled to present themselves to be in need of assistance, and were often unable to access appropriate and tangible support from housing services. It is possible that those who present as homeless at the same time as being in work may be deemed not vulnerable and in need of support. As a result, many participants were 'on their own'.

You're working full-time and you're trying to make ends meet...you're having to do things off your own back and it's not fair (Respondent 9)

Follow up interviews suggested that with no other options, some participants had alternated between rough sleeping, sofa-surfing, and sleeping in cars and caravans. Some had moved into accommodation which they considered unsuitable. One participant, for example, felt they had no choice but to move into private rented accommodation which they feared would have an adverse impact on their family's health:

[W] e've actually found a house, even though I don't think it's suitable. It's got no central heating in it and it's got damp in it, my son's got asthma (Respondent 8)

Another participant had taken on personal debt in order to access accommodation. Whilst alleviating the immediate threat of homelessness, their need to access accommodation quickly had resulted in them taking on a property they struggled to afford in the longer run, despite working long hours:

I got an overdraft for about £1,150... That's probably why I'm in the situation I'm in now...it feels like I'm squatting in this flat... I'm constantly fighting the battles of my overdraft because I can't afford to pay it back... I'm really working overtime... I'm housed but financially I'm not in a good place...[but] I was in a situation where I didn't have any options. (Respondent 4) 
For others, support from family and friends proved crucial. One participant, for example, considered themselves very 'lucky' to have been supported by a colleague:

I stayed [with my colleague]... for two weeks, which gave me the rest of the time that I needed to build up what was effectively the rent thing. I just took the first, cheapest place that I could find, so I'm in there now... he's helped me out massively... it worked out massively, but I think I was just lucky (Respondent 3)

These experiences of 'going it alone' expose the failings of housing policy in practice for those experiencing homelessness at the same time as being in work.

\section{Conclusions and policy implications}

Alongside an increasing focus on 'prevention', paid work is frequently presented as an important part of the 'solution' to homelessness. However, there is growing concern about the phenomena of 'in-work homelessness', a topic on which research is scarce. In this article, we have contributed to the literature in this area by providing a critical examination of how homelessness policy operates in practice, through of the experiences of a marginalised group (working homeless people as service users).

Our paper should challenge simplistic policy assumptions that employment provides the 'solution' to homelessness. In our study, respondents who were working and facing or experiencing homelessness struggled to live on low, sometimes precarious incomes and presented themselves as lacking options excluded from support to move out of, or away from, homelessness. Indeed, despite policymakers emphasising 'work' as a solution to homelessness, we have highlighted a number of ways in which a number of policies and aspects of service provision practices, including those focused on prevention, can in fact work against those who are in work at the same time as facing homelessness. For example, whilst assistance was offered to all participants as per the prevention agenda, support was typically inappropriate to their needs as workers: there were a lack of suitable and affordable housing options close to places of work, support to find accommodation in the private rented sector was often frustrated through the exclusionary practices of landlords who refuse to let to those on low incomes and/or in receipt of benefits, and offers of hostel spaces and temporary accommodation were considered inappropriate for those trying to hold down a job.

In the absence of appropriate support from the housing service, we have shown that those experiencing 'in-work homelessness' have no choice but to rely on alternative resources accrued through personal networks and access to credit. This is arguably not a surprising outcome of a liberal welfare regime such as the UK, where the emphasis is both on 'economic self-reliance' and a non-interventionist approach to labour market regulation (Lohmann and Marx, 2008). However, there are limits to understanding and explaining responses to homelessness and other social issues through welfare regime analysis (Fitzpatrick and Stephens, 2014). For example, a lack of consideration has been given to how socially marginalised groups fare across different welfare regime contexts due, amongst other things, to a tendency for underrepresentation in cross-national statistics. Furthermore, in-work homelessness and in-work poverty both occur across countries which differ in terms of their 'welfare mix' (Lohmann and Marx, 2008; FEANTSA, 2014). Further comparative research is required to understand how the phenomena of 'in-work homelessness' varies in different countries, and how this relates to broader trends of both homelessness and 'in-work poverty'. That said, wherever a system that should prevent and alleviate homelessness fails to support those in work, social and economic policies emphasising work as a route out of poverty and homelessness are undermined.

In emphasising the responsibilities of individuals to engage in paid work in order to escape homelessness, policymakers fail to pay adequate attention to broader structural issues including low pay and insecurity and a lack of affordable housing, and how insecurity in both the labour and housing market interact resulting in marginalisation in multiple arenas. There are limits to the extent to which policies designed to prevent and alleviate homelessness can have successful outcomes in the wider 
context of a labour market that increasingly does not provide people with the income they need to escape material deprivation and weather financial shocks (i.e. the need to pull together a deposit at short notice). Extending conditionality and introducing the threat of sanction to those in work and claiming Universal Credit will arguably exacerbate this insecurity. Failure to tackle the issue of landlords discriminating against those claiming Housing Benefit (soon to be Universal Credit) and capping the amount households can access through the benefits system will also mean that even those in work will continue to be excluded from a large section of the housing market.

As a small country with a devolved government but with limited powers over this broader policy context, Welsh homelessness policy can only go so far in delivering on the prevention agenda (Connell et al. 2017; Brewster and Jones, 2018). However, improvements in prevention policy may follow from exploring ways in which the transition from one property to another can be smoothed through financial assistance to deal with the 'shocks' associated with the loss of a property. Policymakers could also work to remove discriminatory barriers through removing the right of landlords to reject those on no or low incomes on the basis of benefit receipt. Most importantly, actions to ensure that labour and housing markets offer 'decent work' and affordable accommodation are paramount.

\section{References}

Batty, E., Beatty, C., Casey, R., Foden, M., McCarthy, L. and Reeve, K. (2015). Homeless people's experiences of welfare conditionality and benefit sanctions, Crisis: London.

Brewster, D., and Jones, R. (2018) 'Distinctly divergent or hanging onto English coat-tails? Drug policy in post-devolution Wales,' Criminology \& Criminal Justice, 19, 364-381.

Busch-Geertsema, V. (2010) Defining and Measuring Homelessness, in FEANTSA (eds) Homelessness Research in Europe. Brussels: FEANTSA

$\mathrm{CIH}$ (2016) The likely impact of the lower overall benefit cap. http://www.cih.org/resources/PDF/Lower_benefit_cap_FINAL.pdf [accessed 28/05/2019]

Connell, A., Martin, S., St Denny, E. (2017) 'How Can Subnational Governments Deliver Their Policy Objectives in the Age of Austerity? Reshaping Homelessness Policy in Wales,' The Political Quarterly $88,443-451$.

DWP (2018) Universal Credit: In-Work Progression Randomised Controlled Trial. Research Report 966. London: Department for Work and Pensions https://assets.publishing.service.gov.uk/government/uploads/system/uploads/attachment data/file/739 775/universal-credit-in-work-progression-randomised-controlled-trial-findings-from-quantitativesurvey-and-qualitative-research.pdf [accessed 28/05/2019]

Dwyer, P. and Wright, S. (2014) 'Universal credit, ubiquitous conditionality and its implications for social citizenship,' Journal of Poverty and Social Justice, 22, 27-35.

Eurostat (2018) In-work poverty in the EU. https://ec.europa.eu/eurostat/web/products-eurostat-news//DDN-20180316-1 [accessed 28/05/2019]

FEANTSA (2007). Multiple barriers, multiple solutions: inclusion into and through employment for people who are homeless. Brussels: FEANTSA.

FEANTSA (2014) Extent and profile of homelessness in European Member States: a Statistical update. Brussels: European Observatory on Homelessness.

FEANTSA (2018) Third Overview of Housing Exclusion in Europe 2018. Brussels: FEANTSA 
Fitzpatrick, S. and Stephens, M. (2014) 'Welfare Regimes, Social Values and Homelessness: Comparing Responses to Marginalised Groups in Six European Countries,' Housing Studies, 29, 215234.

Fitzpatrick, S., Pawson, H., Bramley, G., Wilcox, S. and Watts, B. (2016) The homelessness monitor: Great Britain 2016. London: Crisis/Joseph Rowntree Foundation.

Fitzpatrick, S. and Watts, B. (2018) Final findings: Social Housing (fixed-term tenancies). http://www.welfareconditionality.ac.uk/wp-content/uploads/2018/05/39273-Social-housing-web.pdf [Accessed 28/05/2019].

Gerrard, J. (2017) Precarious enterprise on the margins: work, poverty and homelessness in the City. Palgrave Macmillan.

Hick, W. and Lanau, A. (2018) 'Moving in and out of in-work poverty in the UK: An analysis of transitions, trajectories and trigger events,' Journal of Social Policy, 47, 661-682.

Homeless Link (2016). Support for single homeless people in England: Annual Review 2016. London: Homeless Link.

Hough, J. Jones, J. and Rice, B. (2013). Longitudinal qualitative research on homeless people's experiences of starting and staying in work. London: Broadway.

Johnsen, S. and Watts, B. (2014) Homelessness and poverty: reviewing the links. Heriot-Watt University.

Jones, K. (2019). 'No strings attached? An exploration of employment support services offered by third sector homelessness organisations', in Dwyer, P. (eds) Dealing with welfare conditionality. Bristol: Policy Press.

Lloyd, C. and Mayhew, K. (2010). 'Skill: the solution to low wage work?,' Industrial Relations Journal, $41,429-445$.

Lohmann, H. and Marx, I. (2008) 'The different faces of in-work poverty across welfare state regimes', in Andre $\beta$, H. J. and Lohmann, H. (eds.), The Working Poor in Europe, London: Edward Elgar.

McNaughton, C. (2008). Transitions through homelessness: lives on the edge. Basingstoke: Palgrave Macmillan.

Ray, K., Sissons, P, Jones, K. and Vegeris, S. (2014) Employment, pay and poverty: An evidence review, York: Joseph Rowntree Foundation.

Scheerhout, J. (2017). Prime Minister Theresa May vows to spend $\$ 500 \mathrm{~m}$ to help the homeless, during visit to Stockport. Manchester Evening News. https://www.manchestereveningnews.co.uk/news/greater-manchester-news/prime-minister-theresavows-spend-12971625 [accessed 25/01/2018]

Shelter (2018) Over half of homeless families in England are in work, shock new figures show http://media.shelter.org.uk/press_releases/articles/over_half_of_homeless_families_in_england are i n_work,_shock_new figures_show [accessed 31/01/2019]

Shelter (undated) Stop DSS Discrimination: Ending prejudice against renters on housing benefit. https://england.shelter.org.uk/_data/assets/pdf_file/0009/1581687/Stop_DSS_Discrimination_Ending_prejudice_against_renters_on_housing_benefit.pdf [accessed 28/05/2019]. 
Shier, M., Jones, M. and Graham, J. (2012) 'Employment Difficulties Experienced by Employed Homeless People: Labor Market Factors That Contribute to and Maintain Homelessness,' Journal of Poverty, 16, 27-47.

Shin, M., Baumohl, J. \& Hopper, K. (2001) 'The prevention of homelessness revisited,' Analyses of Social Issues and Public Policy: 95-127.

Standing, G. (2011) The Precariat: The New Dangerous Class. London: Bloomsbury

Tinson, A., Ayrton, C., Barker, K, et al. (2016) Monitoring Poverty and Social Exclusion 2016. York: Joseph Rowntree Foundation. 